\title{
ЦЕНООБРАЗОВАНИЕ БАНКОВСКОГО КРЕДИТА - КАК ЭЛЕМЕНТ СТИМУЛИРОВАНИЯ КРЕДИТНОЙ ДЕЯТЕЛЬНОСТИ В ЭКОНОМИКЕ: ФАКТОРЫ ВОЗДЕЙСТВИЯ И РАЗВИТИЕ МЕХАНИЗМА
}

\author{
(c) 2021 Тибилова Зарина Вадимовна \\ аспирант кафедры «Финансы и кредит» \\ Северо-Осетинский государственный университет имени Коста Левановича Хетагурова, \\ Россия, Владикавказ \\ E-mail: finansikredit@yandex.ru
}

В статье рассматривается проблематика системности формирующихся цен на банковские кредиты, уточняется влияние затратной составляющей экономики, факторное воздействие коммерции, зависимости кредитного потенциала банков от выбираемых и используемых методов дифференциации кредитов заемщикам. Предлагаются обоснования в подходах, направленных на активизацию кредитной деятельности коммерческих банков с обеспечением исполнения ими общих равнонаправленных требований, устанавливаемых ЦБ РФ. Результативность использования цены кредита рассматривается во взаимосвязи с его стоимостью. Проведен анализ разнообразных составляющих регулирования цен на кредиты, в том числе, с учетом инфляционной проблематики и нахождения позитивных изменений существующей практики.

Ключевые слова: кредит, цена, банки, кредитная деятельность, регулирование, результативность, инфляция, индикаторы, показатели.

Цена банковского кредита формируется под влиянием множества экономических факторов, основу которых составляют затраты на товарное производство и услуги. Если в экономике «раскручивается» затратная составляющая, тогда и вероятность роста цены кредита усиливается. В таком контексте необходимо в большей мере учитывать, что стоимость кредита формируется в экономике (экономически), а цена кредита в банковской сфере. Значит, всякое нарушение прямой связи между платой за кредит (банковский кредит) и его стоимостью у заемщиков будет диктовать условия противоречивого характера используемого кредита.

Отдельный банк, тем более коммерческий, оказывает воздействие на цену кредита с учетом платности, срочности, возвратности и объемов выделяемых кредитных средств различной категории заемщиков. Собственные установки коммерческого рынка, как правило, коммерциализируются. Однако, надо иметь ввиду и то, что в зависимости от кредитного потенциала банка дифференциация выделяемых кредитов может расширяться, и это следует расценивать в качестве одной из особенностей кредитной деятельности коммерческих банков. Законодательно не следует ограничивать расширение банков- ской самостоятельной кредитной деятельности в пределах указанного дифференцированного подхода к решаемым задачам.

Нормативы, устанавливаемые ЦБ РФ в целях регулирования коммерческой банковской деятельности, безусловно имеют свое воздействие на их кредитную практику. Их целостное соблюдение направлено на то, чтобы обеспечивать исполнение банками общих равнонаправленных требований, в том числе, в использовании кредита. Кредит - ресурс, который аккумулируется в банках. Цены, формируемые на него, не должны быть централизованно устанавливаемыми, но в их использовании коммерческими банками возникают задачи централизованного регулирования с одновременным расширением банковской самостоятельности кредитной деятельности. ЦБ РФ своей регулирующей деятельностью (используя соответствующие нормативы) ограждает банки от всякого внешнего вмешательства со стороны других органов власти в стране и тем самым усиливает их (банков) самостоятельность.

Права банков в установлении цены кредита должны быть достаточны для осуществления коммерческих задач в той мере, которая зависит от их кредитной деятельности. В тоже 
время управление процессом формирования цен на кредит включает учет устанавливаемой ключевой ставки ЦБ РФ. Ключевая ставка - это ориентир для формируемых цен кредита коммерческими банками в качестве государственно - общественно устанавливаемого значения цены используемых в экономике денег (кредит измеряется деньгами и это фиксируемо в стоимостной определенности). Формула ключевой ставки носит характер не установления конкретных цен на кредиты, которые выделяются коммерческими банками, а требований определенности условий сбалансированности используемых кредитных ресурсов. В таком качестве ключевая ставка влияет на равновесие цен кредита в банках и системность ценообразования на кредиты. Добавим и то, что использование в банковском регулировании ключевой ставки способствует избеганию крайностей в банковской кредитной деятельности.

Цена кредита подвержена частым изменениям, что происходит под влиянием различных факторов неравномерного воздействия. Положительную роль влияния таких факторов не следует оценивать только с позиций снижения цены кредита, хотя это бывает востребованным от заемщиков. Снижающиеся цены на кредит могут иметь оправданность в той мере, в которой результативность используемого кредита оказывается возрастающей. Если же сохраняется статичное состояние показателей результативности, тогда следует искать дополнительные объяснения происходящим процессам используемого кредита и его цены в динамике роста.

Рост цены кредита может быть оправданным, если его изменения способствуют реализации количественных и качественных показателей развития экономики. Как правило, системность ценообразования на кредиты реагирует на стабильный рост цен кредита в определенные периоды, совпадающие с тенденциями экономического развития, подтверждающие положительную динамику его отдачи, отражающейся в соответствующих показателях в динамике. Это же, в свою очередь делает банковский кредит более востребованным. Достижение таких результатов по условиям находится как в пределах эффективной банковской кредитной деятельности, так и реальной экономической практики. Достижение конечной результативности отдачи находится в пределах возможностей приближения банками цены кредита к интересам товаропро- изводителей и производителей услуг. Не оправдана практика, когда более высокая или низкая цена кредита превращается в «служанку» сугубо локальных интересов, без всякого установления контроля над его (кредита) использованием.

Дестабилизирующим фактором, влияющим на системную обоснованность банковского кредита, может быть резкое увеличение (рост) цены кредита. Такая проблематика касается не односторонней деятельности коммерческих банков (например, максимальное получение прибыли от проведения ссудных операций). Если банк (а тем более все банки) резко повышают банковские проценты платы за кредит, то неминуемо увеличивается разрыв между средневзвешенной ценой кредита и заработком доходов в экономке. Такой разрыв неминуемо скажется на отрицательно развивающемся процессе использования кредита заемщиками, для которых, к тому же, кредит может иметь разное значение. Под последним нами имеется виду имеющиеся разные зависимости заемщиков в использовании кредита.

Отметим еще раз, что рост кредитных ставок является фактором прямого воздействия на цену кредита для заемщиков. Отдельный банк может прилагать усилия в сдерживании роста цены выделяемого кредита своим заемщикам даже при росте процентной ставки на него. Вместе с тем, не следует преувеличивать значения таких усилий если у банка возникает проблема расширения кредитного спрэда (разрыв между процентными ставками и депозитами банка). Расширяющиеся показатели банковского спрэда способствуют удорожанию кредита, т.е. росту его цены. На конец 2020 года по банковскому спрэду в России кредитный спрэд достиг 5,21\%, в то время как в развитых банковских системах зарубежных стран он оставался в пределах 2-5\% [1].

Оценивая банковскую кредитную деятельность, чрезвычайно важно иметь ввиду, что каждый банк сталкивается с изменяющейся проблематикой используемых ресурсов, в том числе и кредитных. Если для банка более дорогими становятся пассивы по облигационным займам, депозитам юридических лиц, вкладам населения, то вероятность проявленной его активности в росте цены кредита не только возникает, но и начинает себя реально проявлять. Конечно, действия банка будут направлены на покрытие роста своих расходов в первую очередь, но одновременно же и на получение до- 
Таблица 1. Ключевая ставка Банка России, (\% годовых)

\begin{tabular}{|c|c|}
\hline Начало действия & Ставка \\
\hline 16.09 .2013 & 5,50 \\
\hline 03.03 .2014 & 7,00 \\
\hline 28.04 .2014 & 7,50 \\
\hline 28.07 .2014 & 8,00 \\
\hline 05.11 .2014 & 9,50 \\
\hline 12.12 .2014 & 10,50 \\
\hline 16.12 .2014 & 17,00 \\
\hline 02.02 .2015 & 15,00 \\
\hline 16.03 .2015 & 14,00 \\
\hline 05.05 .2015 & 12,50 \\
\hline 16.06 .2015 & 11,50 \\
\hline 03.08 .2015 & 11,00 \\
\hline 14.06 .2016 & 10,50 \\
\hline 19.09 .2016 & 10,00 \\
\hline 27.03.2017 & 9,75 \\
\hline 02.05 .2017 & 9,25 \\
\hline 19.06.2017 & 9,00 \\
\hline 18.09 .2017 & 8,50 \\
\hline 30.10 .2017 & 8,25 \\
\hline 18.12 .2017 & 7,75 \\
\hline 12.02 .2018 & 7,50 \\
\hline 26.03 .2018 & 7,25 \\
\hline 17.09.2018 & 7,50 \\
\hline 17.12.2018 & 7,75 \\
\hline 17.06.2019 & 7,50 \\
\hline 29.07 .2019 & 7,25 \\
\hline 09.09 .2019 & 7,00 \\
\hline 28.10 .2019 & 6,50 \\
\hline 16.12.2019 & 6,25 \\
\hline 10.02 .2020 & 6,00 \\
\hline 27.04 .2020 & 5,50 \\
\hline 22.06 .2020 & 4,50 \\
\hline 27.07.2020 & 4,25 \\
\hline 22.03 .2021 & 4,50 \\
\hline 26.04 .2021 & 5,00 \\
\hline 15.06 .2021 & 5,50 \\
\hline 26.07 .2021 & 6,50 \\
\hline 13.09 .2021 & 6,75 \\
\hline 25.10 .2021 & 7,50 \\
\hline
\end{tabular}


полнительной прибыли. Вопрос в нахождении наиболее приемлемого варианта принимаемых решений в кредитовании. Строгость и выверенность действий банка будет в том, чтобы не «перепутать» располагающие свои возможности в наличии кредитного ресурса и те отношения, которые возникают у него с клиентами. Перегибами в удорожании платы за кредит можно связать свою же деятельность «по рукам и ногам», что отзовется на ценовой стороне кредита отрицательно.

Естественно, возникают и отдельные узловые вопросы цены банковского кредита, которые формируются под влиянием общих тенденций инфляции (денежной), межбанковской конкуренции на кредитном рынке. Коммерческие банки как правило реагируют на инфляцию и ее темповую динамику с позиции влияния на процентные свои расходы. Это неминуемо, так как инфляция денег не только воплощается в росте цен, но и оказывает отрицательное влияние на вклады населения. Банки, теряя возможности увеличения кредитных доходов (доходы от используемых кредитов - ресурса), начинают уходить в отрицательные показатели по депозитам (снижают их), а вкладчики средств в банках (население) теряют стимулы от банков, размещая в них меньше средств. Если эти противоречия не снимаются методами банковского регулирования, применяемыми ЦБ РФ, тогда резко могут изменяться позиции банковской кредитной деятельности в стране. Снижение показателей кредитного обеспечения экономики (в широком смысле), разумеется, будет отрицательно влиять и на деятельность самих банков вплоть до закрытия определенной их части, оказывающейся с наименьшим кредитным ресурсным потенциалом.

ЦБ РФ, при возникновении ухудшающихся позиций общей кредитной деятельности банков, не стремится к таким изменениям регулирующего воздействия, которые только направлены к удерживанию ценового роста кредита. В регулирующей деятельности ЦБ РФ это всегда имеется ввиду, но сдерживание роста инфляции (ее таргетирование) осуществляется с позиций общего состояния денежно-кредитной составляющей в стране. ЦБ РФ, в том числе, и с учетом динамики показателей цены кредита, исходит из того, что в долгосрочном измерении снижение инфляции неминуемо будет способствовать уменьшению процентных расходов коммерче- ских банков, а значит они будут стремиться зарабатывать не меньшие доходы от кредитной деятельности, базирующейся на более дешевом (по платности) кредите. Общая систематизация ставок на кредиты коммерческих банков, как нами ранее отмечалось, происходит вслед за установлением ключевой ставки ЦБ РФ.

Коммерческие банки обязаны больше внимания уделять формированию своих кредитных ресурсов и не только с позиции цены кредита, но и возможностей, и целесообразностей ее изменений. Проблематика кредита и кредитной деятельности не выходит за пределы общих целей и задач, которые реализуют банки. Если это так, тогда устанавливаемую отдельным банком цену кредита необходимо оценивать и с позиции, как средневзвешенной стоимости сформированного банком капитала, так и требований для системной деятельности. Напомним, что речь идет о базовых нормативах регулирования банковской коммерческой деятельности: достаточность собственного капитала банка Н1.0 (в размере 8,0\%); базовый капитал банка Н1.1 (в размере 4,5\%); основной капитал Н1.2 (в размере 6,0\%). Соблюдение требований исполнения этих нормативов определяет предварительные и последующие условия формирования пассивов коммерческих банков и это, разумеется, оказывает влияние на их кредитный потенциал и последующую кредитную деятельность по цене.

Относительные показатели, складывающиеся в формировании пассивов коммерческих банков в длительном цикле (за 3 года и более) на основе указанных нормативов регулирования банковской деятельности, как правило, показывают их устойчивость в кредитовании, если иметь в виду ценовые изменения ключевой ставки, устанавливаемой ЦБ РФ. Одновременно же они выступают в качестве индикаторов воздействия на сформированность и применяемость процентной ставки по кредитам коммерческих банков в допустимо приемлемых границах, чтобы банки не уходили в минус по доходам (при соблюдении нормативов), или в отрыв удорожания цены кредита. Такое непрямое регулирование цены кредита оправдано не только с точки зрения развития системности банковской кредитной деятельности, ее стимулирования, но и общеэкономического интереса в налогообложении доходов коммерческих банков. На практике имеет место развивающаяся связь 
Таблица 2. Структура пассивов банковской системы, млрд. руб.

\begin{tabular}{|l|c|}
\hline \multicolumn{1}{|c|}{ Наименование статей пассивов } & 9593,4 \\
\hline Фонды и прибыль кредитных организаций & 2451,4 \\
\hline $\begin{array}{l}\text { Кредиты, депозиты и прочие привлеченные средства, } \\
\text { полученные кредитными организациями от Банка } \\
\text { России }\end{array}$ & 700,3 \\
\hline Счета кредитных организаций & 8147,1 \\
\hline $\begin{array}{l}\text { Кредиты, депозиты и прочие средства, полученные } \\
\text { от других кредитных организаций }\end{array}$ & 63435,5 \\
\hline Средства клиентов & 30411,9 \\
\hline Вклады физических лиц & 10103,7 \\
\hline Средства организаций на расчетных и прочих счетах & 21704,4 \\
\hline $\begin{array}{l}\text { Депозиты и прочие привлеченные средства юриди- } \\
\text { ческих лиц }\end{array}$ & 1215,5 \\
\hline Прочие средства клиентов & 2852,7 \\
\hline Ценные бумаги & 9400,7 \\
\hline Прочие пассивы, всего & 96581,1 \\
\hline Всего пассивов & \\
\hline
\end{tabular}

(скажем так - изменчивая) между ставками по депозитам и минимальной процентной ставкой по кредитам, которую ЦБ РФ регулирует через ключевую ставку, меняя ее, (в таблице 1 приводятся данные изменений ключевой ставки за период с 2014 по 2021 годы (данные 2021 года на 1 ноября)).

Разумеется, каждый норматив банковского регулирования имеет его влияние на размеренность кредитной деятельности и требует детального самостоятельного анализа. В тоже время есть и общие основания в наборе факторов, которые в большей или меньшей степени формируют позиции банков в кредитной деятельности. Например, размер необходимого коммерческому банку для деятельности капитала в целом формируется под влиянием следующих факторов: общей суммы вкладов физических лиц; средств организаций на счетах; депозитов; ресурсов Банка России; доходов от собственной деятельности (прибыли); резервов на возможные потери и др. При изменении этих показателей каждый раз будет возникать проблематика не только достаточности капитала банка по установленному нормативу ЦБ РФ, но и уровня, а также динамики показателей кредитной деятельности. Важно то, как структурное соотношение капитала банка и структурное составляющее пассивов банков по видам аккумулированных (сформированных) ресурсов происходит. Для расширения кредитования необходимо, чтобы в положительной динамике оказывалось соотношение краткосрочных и долгосрочных источ- ников формирующихся ресурсов, но с учетом цены привлекаемых ресурсов на рынке. В таблице 2 приведены данные, характеризующие составляющие структуры пассивов банковской системы РФ на конец 2020 года [1].

Крупный вопрос - востребованность кредита и его согласование в банковской деятельности с разницей привлеченных и предоставляемых средств клиентам по реализуемым условиям кредитования: платность, сроки. На 01.01.2020 года, по данным ЦБ РФ [1] средства, поступившие в коммерческие банки от их клиентов, составили 54,964 млн. рублей, а предоставленные в качестве кредитов 53,175 млн. рублей. Разница $-1,789$ млн. рублей, что укрепляло для последующего периода позиции выделения кредитов. Указанные показатели формировались под влиянием разных факторов: поступление средств - под влиянием выгоды по депозитам, а выдача кредитов - из-за низкого уровня наращивания масштабных резервов клиентов в долгосрочном измерении. Можно констатировать, что механизм трансформации привлеченных средств в долгосрочные кредитование остается актуальным для совершенствования. Кредитная деловая активность не может развиться в необходимой и достаточной степени, если в коммерческом кредитовании будет превалировать использование потребительского кредита, хотя и это чрезвычайно важно.

Потребительское кредитование зависит от имеющегося кредитного потенциала банков, которые им занимаются. В тоже время надо иметь 


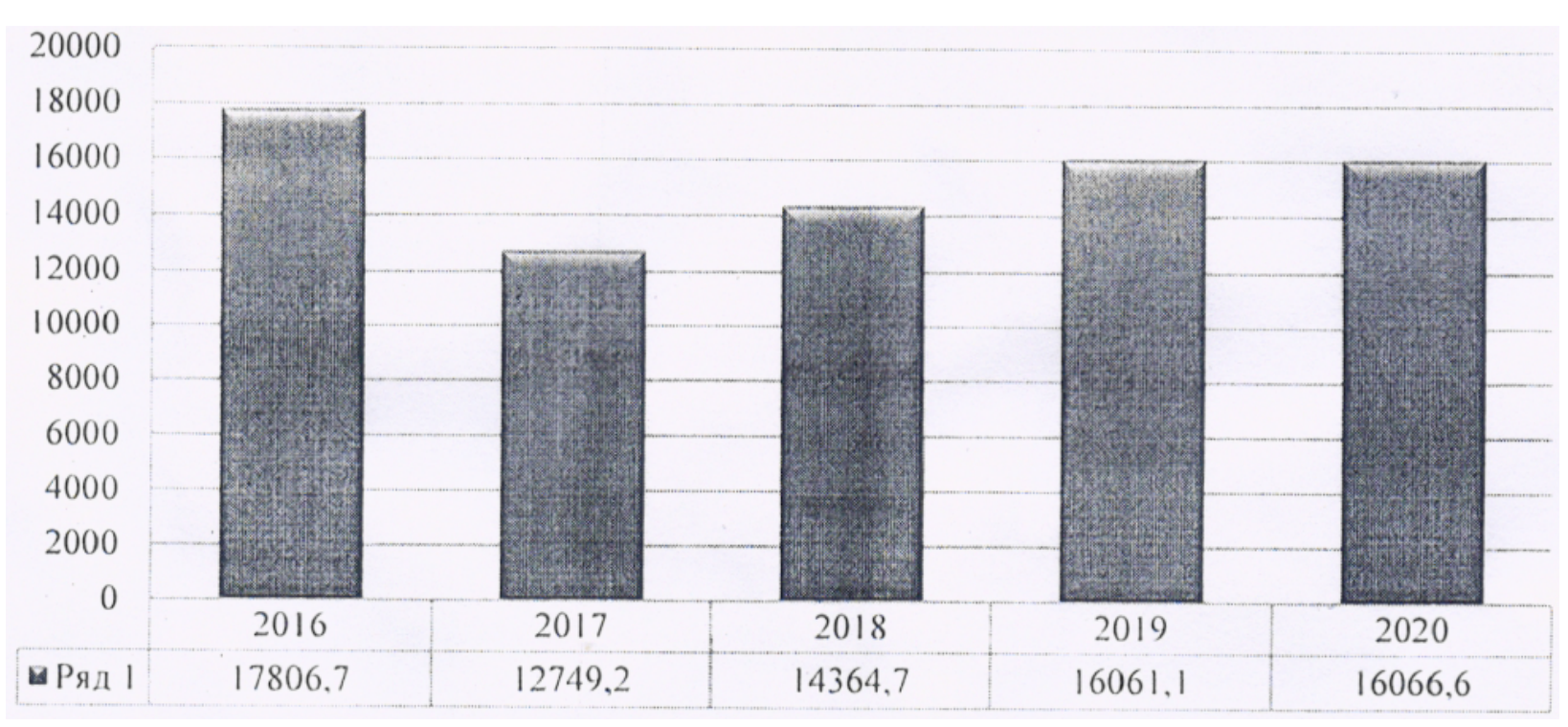

Puc. 1. Динамика количества предоставленных потребительских кредитов, тыс. ед. Источник: на основе данных www.vaael.ru/pdf/2020/9-2/713.pdf)

ввиду как его востребованность, так и доступность для своевременного получения заёмщиками как по цене, так и в объемном измерении. K этому надо добавить проблематику количественных значений заемщиков и предоставляемых кредитов по срокам их возвратности. На рисунке 1 приводятся данные, характеризующие количество предоставленных потребительских кредитов (тыс. ед.) в период с 2016 по 2020 годы [2]. Наблюдается закономерность: при снижении ключевой ставки ЦБ РФ и ставок коммерческих банков, как правило, количество предоставленных потребительских кредитов растет. Значительное влияние на рост потребительских кредитов оказывают инфляция и инфляционные ожидания, что имело место в период с 2015 по 2020 годы.

При росте показателей ликвидности коммерческих кредитных организаций и относительно низком уровне использования механизма долгосрочного кредитования за счет привлеченных в банки средств, как показывает практика, рост цены кредита возможен, но эффективность его экономического использования снижается. Этому есть объяснение и не только с позиции степени трансформации привлеченных в коммерческие банки средств в общей их суммарной динамике. В банковской практике России в последние годы существует не только общая тенденция роста потребительских кредитов, но и особенности ценообразования на них. Накопленный объем выданных потребительских кредитов только в 2020 году составил 14,6 млн. рублей, но нет достоверных данных сколько из них выдано без обеспечения. ЦБ РФ фиксирует общую тенденцию роста потребительского кредитования, так же, как и портфеля необеспеченных потребительских кредитов в российской банковской системе, но не уточняет динамику значений показателей. В то же время получается так, что ликвидность коммерческого банковского сектора поддерживается расширением значимости тех цен, которые касаются потребительского кредита. Во многом такая практика сдерживает возможности сокращения процентных ставок за счет той прибыли, которую коммерческие банки получают в результате частого кратковременного роста цен на выдаваемые заемщикам кредитов. Ключевая ставка ЦБ РФ на такую практику реагирует в основном, как известно, с позиции таргетирования инфляции, что отчасти, но не всегда является фактором сдерживания роста цен не только на кредиты, но и на товары, а также услуги.

В октябре 2021 года ЦБ РФ провела ежегодную конференцию, на которой доложил свою позицию видения регулирующего воздействия на параметры и динамику инфляции, подверженного значительным влиянием переменных факторов [1]. В таком контексте особый акцент был сделан на новой стратегии целевого показателя инфляции, который будет применяться Банком России при принятии соответствующих решений. При этом исходная позиция обозначена так: «стабильность цен лучше всего поддерживать, преследуя целевой показатель инфляции в размере 
4\% в среднесрочной перспективе» [1]. Напомним в этой связи, что до июля 2021 года целевой показатель применялся в пределах 5-6\%, но его на указанной конференции оценили, как способствовавший асимметрии в денежно-кредитном регулировании и не удерживающим стабильность использования денег в экономике в пределах ниже 5\% на годовом уровне.

Подчеркнем еще раз, что неэффективное регулирование темпов, уровня и динамики показа- телей инфляции резко обостряет не только всю практику использования кредита, по цене, стремящейся к росту, но и имеет свою размерность влияния на рыночные цены в их совокупности. Как следствие, возникает расширенная практика раскрутки цен, охватывающая не только все движение товаров и услуг, но относительно мало влияющая на экономическую эффективность их издержек.

\section{Библиографический список}

1. https://cbr.ru/

2. www.vaael.ru/pdf/2020/9-2/713.pdf

3. Кулумбекова Т.Е., Токаева Т.И., Тибилова 3.В. Кредитные ресурсы банковской системы: формирование, ограничения, риски и показатели использования. Северо-Осетинский государственный университет имени К. Л. Хетагурова. Владикавказ, 2019.

4. Сугарова И.В., Алборова А.Э. Анализ банковской системы России на основе количественных и качественных показателей//Экономика и предпринимательство. 2016. № 11-4(76). С 141-146.

5. Сугарова И.В., Тиникашвили Т.Ш. Роль банковской системы в экономическом развитии региона. В сборнике: Повышение роли банков в обеспечении экономического роста и развития в регионах. Сборник материалов научно - практической конференции. 2012. С. 73-81.

6. Токаев Н.Х., Койбаева М.Х., Царахова Д.Б. Влияние фактора цены на формирование продуктового ряда банковских услуг//Управление экономическими системами: электронный научный журнал. 2013. № 12(60). C. 64.

7. Токаев Н.Х., Чибаева М.О. Банковское кредитование: факторы возрастающего значения и проблематика ресурсного обеспечения. В сборнике: Актуальные проблемы современной науки. Сборник научных трудов по материалам Международной научно - методической конференции. 2019. С. 219-222. 